\title{
A Three-Dimensional Thermo-Chemical Characterization During the Whole Curing Cycle of a Carbon / Epoxy Prepreg
}

\author{
Rima Sfar Zbed, Vincent Sobotka and Steven Le Corre
}

\begin{abstract}
Rima Sfar Zbed. Université de Nantes, CNRS, Laboratoire de Thermique et Energie de Nantes, LTeN, UMR 6607, F-44000 Nantes Corresponding author: rima.sfar-zbed@univ-nantes.fr

Vincent Sobotka. Université de Nantes, CNRS, Laboratoire de Thermique et Energie de Nantes, LTeN, UMR 6607, F-44000 Nantes Steven Le Corre. Université de Nantes, CNRS, Laboratoire de Thermique et Energie de Nantes, LTeN, UMR 6607, F-44000 Nantes
\end{abstract}

\begin{abstract}
Mitigation of cure-induced defects in thermoset composite parts has always been a challenging problem for manufacturers especially when it comes to high dimensional accuracy of components. Thus, it is crucial to understand the evolution of the thermo-chemical properties of these materials during the totality of the curing cycle. In this paper, a new methodology is presented to characterize the process-induced strains throughout the cure. The investigation is based on the development of an existing laboratory bench named as PvT-HADDOC. The tests were performed on an interlayer toughened aerospace carbon/epoxy prepreg. Unidirectional laminate samples $\left(105 \times 105 \mathrm{~mm}^{2}\right)$ of almost $6 \mathrm{~mm}$ of thickness were manufactured by hand layup then debulked at room temperature under full vacuum. The PvT-HADDOC device allows a manufacturing process following the recommended cure cycle of epoxy composites under 7 bars pressure and a temperature up to $180^{\circ} \mathrm{C}$. It enables the measurements of the process-induced strains, simultaneously, along two directions: through-thickness and in-plane. Results show a complex behavior of an assumed unidirectional composite. It exhibits a temperature and time dependent compaction behavior through the thickness only. The measured thermal expansion coefficients are proved to be higher in the thickness direction for the uncured as well as for the cured state of the material. Most of the chemical shrinkage occurs along the thickness direction. This unexpected complexity is mainly attributed to the presence of interleaf layers of resin in the laminate structure. Thus, the investigated M21/IMA material is considered fully orthotropic.
\end{abstract}

Keywords. Anisotropy, Curing, Chemical Shrinkage, Thermal Expansion

\section{Introduction}

The composite manufacturing industry faces enormous challenges to understand and control thermosetting composite behavior throughout the production processes. The curing stage is among the most critical step. Cure shrinkage in the thermoset matrix is the major source of cure induced defects in composite parts. Due to its coupling with thermal expansion or contraction, the linear chemical shrinkage is difficult to characterize when it comes to orthotropic materials. The coefficients of chemical shrinkage and thermal expansion (noted CCS and CTE, respectively) are among the significant parameters that are used for numerical simulation of residual stress development and final shape of composite parts. Experimental investigations are usually conducted on partially or fully cured samples limited to single plies of prepregs to estimate these parameters and lack reliable data about the total cure behavior. The aim of this study is to obtain a further understanding of linear thermal expansion and chemical shrinkage developments during the whole cure cycle of composite materials. Hence, a multi-axial investigation of the thermo-chemical behavior of an epoxy/carbon laminate is conducted using a new experimental device.

\section{Experimental}

\subsection{Material and samples}

The studied material in this research is a unidirectional prepreg, HexPly ${ }^{\circledR}$ M21/34\%/UD194/IMA-12K, made of M21 
epoxy resin and IMA carbon fibers with a nominal cured ply thickness of $0.184 \mathrm{~mm}$. The M21/IMA system has the particularity to include an extra layer of resin toughened with thermoplastic particles as a distinct interleaf between plies as shown in Fig. 1. This technique of interleaving has been widely used as a solution to enhance cured laminate toughness. It has shown to give significant improvements of the inter-laminar toughness and the mechanical properties such as the static strength and fatigue resistance $[1,2]$.

Laminate samples used in this investigation were all prepared according to the same conditions. Each specimen is made of 30 plies of the M21/IMA prepreg stacked into a unidirectional configuration by hand lay-up. Squares of 140x140 $\mathrm{mm}^{2}$ were firstly cut from the prepreg, laid-up then placed on a flat aluminum tool and covered with a vacuum bag. The removal of air forces the bag down onto the stacked laminate ensuring a debulking pressure of up to 1 atmosphere. A 2-hours debulk at room temperature was performed on the 30 stacked plies all together. Samples of $105 \mathrm{x} 105 \mathrm{~mm}^{2}$ were finally cut from the debulked assembly and the average initial thickness based on 9 specimens was about 5.96 $\pm 0.05 \mathrm{~mm}$.

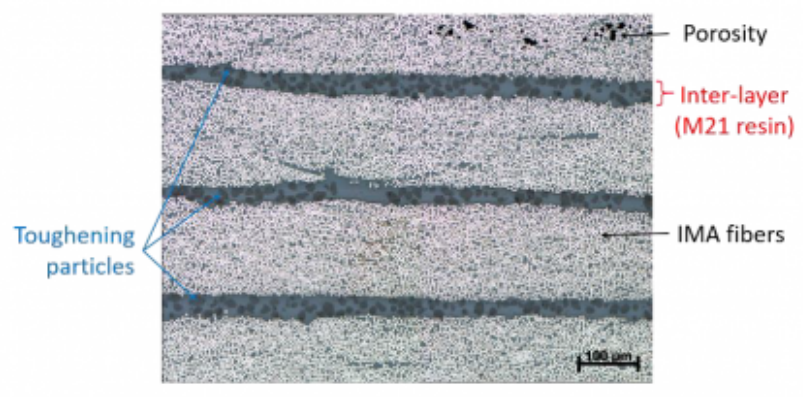

Fig. 1. Micrograph of the thickness of the M21/IMA laminate cured sample

\subsection{Experimental setup}

In this study, the characterization of the process-induced strains throughout the cure of the M21/IMA laminate is carried out using an already existing home-made device named as PvT-HADDOC. A more detailed overview of the working principle of the first version of this device can be found in [3]. This bench consists of a mold cavity assembled to an Instron ElectroPuls E10000 electrical press as presented in Fig. 2-left. The research presented in this paper is based on the improvement of the first version of this bench to enable a homogeneous thermal and mechanical state around the samples while curing.

During the experiment, the mold cavity is filled up with a CALSIL IP 50 silicon oil. The laminate sample is placed between the piston of the machine and a plate that is attached to the lower heat exchanger of the cavity (see Fig. 2-right). The thermal cure cycle applied to the material inside the cavity is ensured by both heat exchangers that are connected to a Vulcatherm thermo-controller unit that allows the heating/ cooling of the system by circulating a fluid through these exchangers. The applied temperature can reach up to $200^{\circ} \mathrm{C}$. The silicon oil circulates continuously through both exchangers to provide the thermal homogeneity around the sample. A compressive hydrostatic stress is applied around the sample throughout the whole cure cycle assuming that the friction on its surfaces is negligible. Thus, it is simultaneously submitted to the compressive force applied by the piston along its thickness combined to the lateral oil pressure. The latter is performed by an external piston allowing to reach 10 bars during the cure and controlled by a local high temperature pressure transmitters 35X HTC inserted in the mold cavity. 
Thanks to this device it is possible to record the dimensional variations of an anisotropic thermoset composite sample during the cure process simultaneously along two directions. The in plane measurements are provided by a laser profilometer KEYENCE LJ-V 7080 placed in front of the glass window of the mold cavity to ensure the recording of the lateral displacements of the sample surface variation as a function of time. The estimation of the in plane deformations of the sample throughout the cure requires an optical correction of the raw data coming from the profilometer as it is detailed and validated in [3] to overcome the refraction phenomena. The dimensional variations of the sample through its thickness direction is measured throughout the displacement of the piston given by the Instron Press. This latter is monitored in constant force mode during the total cure process which enables to follow the variation of the sample thickness.

As presented in Fig.1-right, two heat flux sensors are inserted in the piston and the steel plate so that they are in contact, respectively, with the upper and lower sample surfaces. Data treatment of these sensors, as it is described in [3], provides information about the surface temperatures of the sample and the heat flux exchanged between this latter and the device. It is then possible with this device to estimate the degree of cure of the sample by analyzing these fluxes during the chemical reaction of the material.
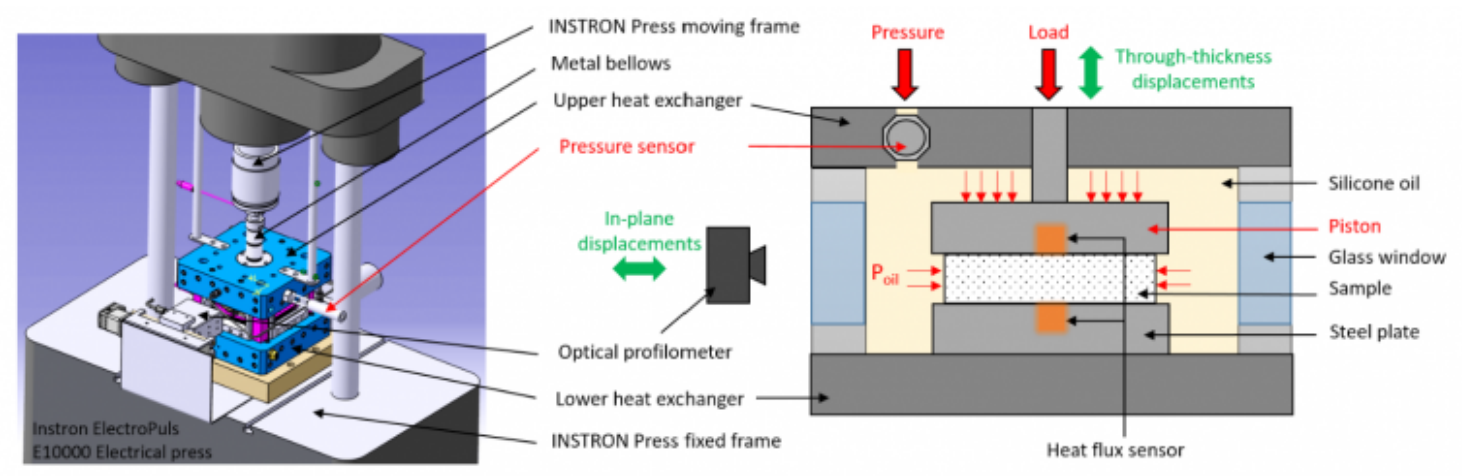

Fig. 2. Global overview of the PvT-HADDOC experimental setup. 3D conception (left) and a scheme of the mold cavity (right)

\section{Experimental results and discussion}

\subsection{Cure kinetics of the M21 resin}

The manufacturer's recommended thermal cure cycle for the M21/IMA system based on the epoxy resin and according to the thickness of laminate samples used in this investigation, consists of a heating ramp of $2^{\circ} \mathrm{C} / \mathrm{min}$ up to $180^{\circ} \mathrm{C}$ and an isothermal curing dwell for $120 \mathrm{~min}$ at this temperature before the cooling stage of the cured material to the ambient temperature. As the crosslinking reaction of the epoxy resin being slow during the curing of the laminate samples, it was not possible to estimate the degree of cure of the material using the HADDOC device. The same issue was observed in previous investigations [3] conducted on a similar prepreg based on the M21 epoxy matrix. In order to obtain a better understanding of the shrinkage development of the studied material during the manufacturing, it is mandatory to well predict the cure kinetics of the matrix. Phenomenological models are generally preferred to study the M21 epoxy system. Relying on the investigation conducted by Msallem [4] to model the cure reaction of the same type of resin, the proposed autocatalytic model of Bailleul [5] was used in this research to estimate the degree of cure of the studied material. It has been extended by Msallem [4] to consider the effects of glass transition temperature on the cure kinetics (Eq. (1)). Model validity was verified on M21 resin samples during the cure for a given pressure and 
A Three-Dimensional Thermo-Chemical Characterization During the Whole Curing Cycle of a...

according to the manufacturer's recommended thermal cycle using the PvT- $\alpha$ mold $[4,6,7]$ that can simultaneously measure the heat flux, the surface temperature and the volumetric change of the resin sample.

$$
\begin{gathered}
d \alpha / d t=G(\alpha) \cdot K_{A}(T) \cdot K_{D}(T, \alpha) \\
G(\alpha)=\sum_{i=0}^{i=7} a_{i} \cdot \alpha^{i} ; \quad K_{A}(T)=K_{r e f} \cdot \exp \left(-A\left(\frac{T_{r e f}}{T}-1\right)\right) ; \quad K_{D}(T)=K_{2} \cdot \exp \left(C_{1}\left(\frac{T-T_{g(\alpha)}}{C_{2}+\left|T-T_{g}(\alpha)\right|}\right)\right) \\
T_{g}(\alpha)=T_{g 0}+\frac{\left(T_{g \infty 0}-T_{g 0}\right) \cdot \lambda \cdot \alpha}{(1-((1-\lambda) \cdot \alpha)}
\end{gathered}
$$

Where $\alpha$ is the degree of cure, $d \alpha / d t$ is the crosslinking rate, $G(\alpha)$ is a polynomial function, $K_{A}(T)$ is the Arrhenius law that describes the dependence of the cure rate on temperature $(T)$ and $K_{D}\left(T_{g}\right)$ is an exponential function that describes the effect of glass transition on the diffusion of macromolecules and the cure kinetics rate. The values of the constants are given in Table 1.

Table 1. Parameters of the kinetics model [4]

\begin{tabular}{ll}
\hline $\mathbf{G}(\alpha)$ & $\mathrm{a}_{0}=0.88, \mathrm{a}_{1}=1.81, \mathrm{a}_{2}=-5.48, \mathrm{a}_{3}=29.26, \mathrm{a}_{4}=138.39, \mathrm{a}_{5}=-232.08$ \\
& $\mathrm{a}_{6}=177.59, \mathrm{a}_{7}=-52.37$ \\
\hline $\mathbf{K}_{\mathbf{A}}(\mathrm{T})$ & $\mathrm{T}_{\mathrm{get}}=493.13 \mathrm{~K}, \mathrm{~K}_{\mathrm{ref}}=0.00164 \mathrm{~s}^{-1}, \mathrm{~A}=19.113$ \\
\hline $\mathbf{K}_{\mathrm{D}}(\mathrm{T}) \quad$ & $\mathrm{K}_{2}=0.335, \mathrm{C}_{1}=2.3, \mathrm{C}_{2}=60 \mathrm{~K}$ \\
& $\mathrm{~T}_{\mathrm{g00}}=215^{\circ} \mathrm{C}, \mathrm{T}_{\mathrm{g} 0}=-4.15^{\circ} \mathrm{C}, \lambda=0.551$ \\
\hline
\end{tabular}

\subsection{Separation of thermal expansion, compaction and cure shrinkage}

\subsubsection{Preliminary curing cycle test}

The M21/IMA prepreg system based on epoxy resin is typically cured following an autoclave curing process. The first laminate sample was cured under a hydrostatic pressure of 7 bars applied in the mold cavity during the whole thermal cycle. The sample was heated from $30^{\circ} \mathrm{C}$ to $180^{\circ} \mathrm{C}$ at a rate of $2^{\circ} \mathrm{C} / \mathrm{min}$ then it was cured for 2 hours at $180^{\circ} \mathrm{C}$ and finally cooled with the same rate to $30^{\circ} \mathrm{C}$. The temperature program and the estimated degree of cure are presented in Fig. 3a. Raw displacements data recorded with the Instron Press were exploited and the through-thickness deformation is calculated (Fig. 3a). The focus here is firstly made on the through thickness strain variation only during the whole cure cycle. Three main phases can be then distinguished according to the material state evolution along the thermal cycle (see Fig. 3a). Phase 1 corresponds to the heating step of the uncured laminate that proved to include more than the thermal expansion of the material. This phase is further studied in the following paragraphs. During phase 2 , the material is isothermally cured at $180^{\circ} \mathrm{C}$ for two hours. The cure shrinkage is observed through the high drop in the measured strain at the start of the isothermal dwell which is directly linked to the crosslinking reaction of the matrix. The strain continue to decrease and remain rather constant during the rest of the isothermal step. In phase 3 , the material is thermally contracted while cooled to the ambient temperature with a rate of $2^{\circ} \mathrm{C} / \mathrm{min}$.

During the first phase, the material exhibits a complex behavior when heated at the uncured state. As it is highlighted in Fig. $3 b$, during phase 1 the through-thickness strain is driven by three competing mechanisms. From $t=1000 \mathrm{~s}$ until almost $t=3000 \mathrm{~s}$, the chemical reaction has not yet advanced $(\alpha=0)$, thus, the chemical shrinkage does not occur at this stage of phase 1 . The two mechanisms observed until $t=3000 \mathrm{~s}$ during the heating are mainly the thermal 
expansion at the liquid state of the material and compaction. This latter dominates over the thermal expansion in this zone where an important drop through the thickness of the material is observed.

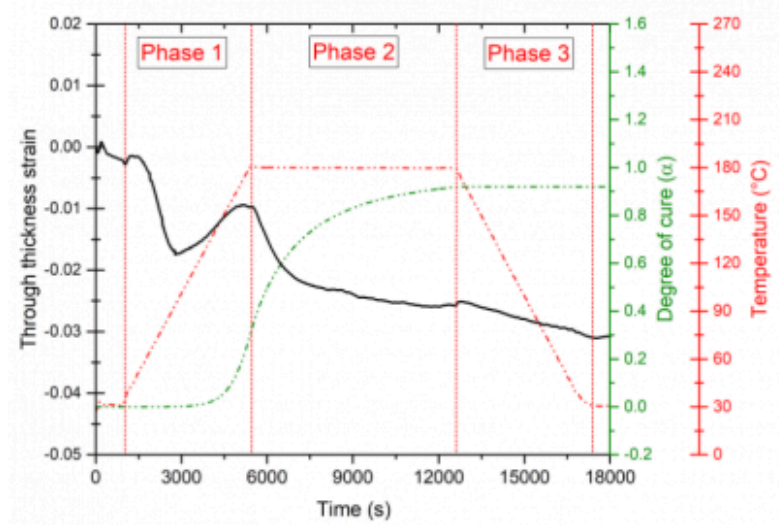

(a)

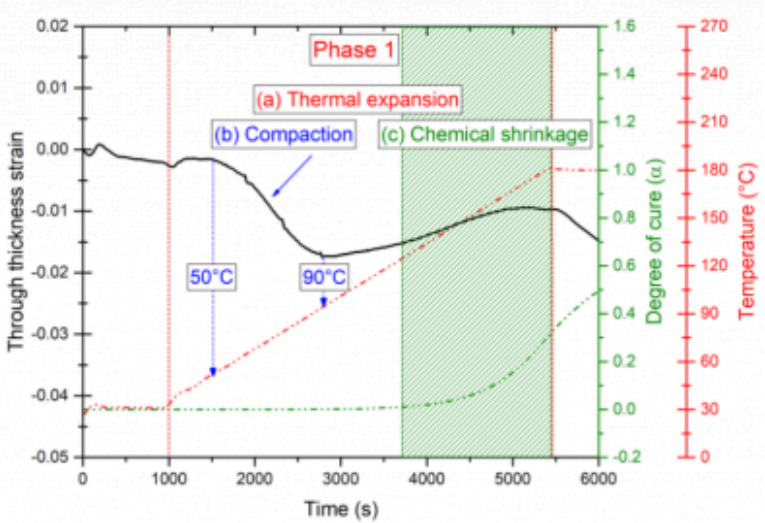

(b)

Fig. 3. Through thickness induced strain. (a) During the whole cure cycle (b) Focus on the phase 1: coupled phenomena

The compaction behavior takes place at an early stage of the heating ramp and the induced strain starts to decrease slightly when the temperature reaches almost $50^{\circ} \mathrm{C}$. Around $90^{\circ} \mathrm{C}$, the material is compacted about $1.7 \%$ and just after, the measured strain starts to increase again mostly due to the thermal expansion of the sample. One can assume that at $90^{\circ} \mathrm{C}$ the material was completely compacted. The increasing of temperature reduces the viscosity of the resin that can exhibit a strong variation up to five orders of magnitude when it comes to interleaved prepregs [8, 9]. The mechanism of compaction prior to curing is a key step during the manufacturing process of thermosetting composite. In this case of study, it is mostly driven by the flow mechanisms of the epoxy resin as a consequence of the thermal heating step under a constant pressure. The compaction process is commonly linked to the impregnation of the fiber bed and the elimination of the inter- and intra-ply air bubbles trapped into the prepreg laminate [10]. This mechanism continues until the composite reaches the maximum compaction of the reinforcement. Starting from $t=3600 \mathrm{~s}$, the cross-linking reaction of the epoxy matrix is activated with temperature and the estimated degree of cure at the end of the heating ramp is almost $\alpha=0.3$. Consequently, at this stage the cure induced strain is affected by a small amount of the chemical shrinkage coupled to the thermal expansion of the material.

Obviously, the simultaneous occurrence of these three physical mechanisms: thermal expansion, compaction and chemical shrinkage during the heating ramp prevents from analyzing the uncured state of the material. In order to distinguish the relative contributions of the thermal expansion driving the through-thickness induced strain during the cure cycle of the M21/IMA laminate, further analyses were performed to separate these phenomena.

\subsubsection{Definition of cure cycles}

Two different thermal histories were tested to cure the prepreg samples. The mechanical state of the sample remains unchanged. Thus, 7 bars pressure is applied during the tested cycles. At this stage, we focused on adjusting the first heating step of the thermal cure cycle. Therefore, during the first modified cycle, a laminate sample was heated from the ambient temperature to $60^{\circ} \mathrm{C}$ with a rate of $2^{\circ} \mathrm{C} / \mathrm{min}$. This temperature was held for $10 \mathrm{~min}$, thereafter, the sample was cooled with same heat rate to the ambient temperature then re-heated again at $2^{\circ} \mathrm{C} / \mathrm{min}$ up to $180^{\circ} \mathrm{C}$. Phase 1 of the cure induced strain in the through thickness direction of laminate sample as well as the thermal cycle and the 
A Three-Dimensional Thermo-Chemical Characterization During the Whole Curing Cycle of a...

estimated degree of cure are presented in Fig. 4.

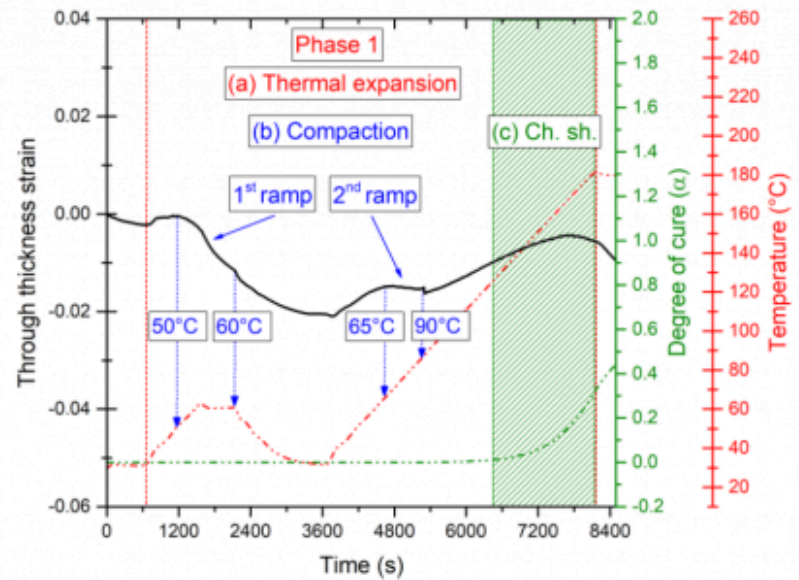

Fig. 4. Focus on the phase 1: Through thickness induced strain during the firstmodified curing cycle

During the first heating ramp, the compaction mechanism starts to take place when the temperature reaches almost $50^{\circ} \mathrm{C}$, as it was observed during the first curing cycle (Fig. 3b). The compaction process continues with a faster kinetics rate during the isothermal dwell at $60^{\circ} \mathrm{C}$ and the sample was compacted through its thickness direction by $1.2 \%$. When re-heated, the material exhibits a second compaction step that starts at $65^{\circ} \mathrm{C}$ with a lower degree of compaction (less than $0.5 \%)$. As observed during the first tested cycle, this mechanism is likely to end when the temperature exceeds $90^{\circ} \mathrm{C}$ (see Fig. $3 \mathrm{~b}$ ). However, we cannot assume that the material reaches a limit of compaction during the heating ramp. Therefore, after $90^{\circ} \mathrm{C}$ and before the start of the crosslinking reaction, the compaction mechanism could alter the thermal expansion behavior of the material at its uncured state. To overcome this issue, a second thermal cycle was tested (is not presented here for sake of simplicity). The isothermal dwell after the first heating ramp was adjusted and fixed at $70^{\circ} \mathrm{C}$ during $30 \mathrm{~min}$. Results showed that the compaction process started during the first heating ramp at the same temperature level $\left(50^{\circ} \mathrm{C}\right)$. The material was compacted by $1.4 \%$ through its thickness until the end of the isothermal dwell. During the second heating ramp the compaction of the material doesn't take place and only thermal expansion mechanism was observed. One can assume that the compaction process is an irreversible mechanism. When the isothermal dwell is held for a sufficient time at a temperature level that is linked to a pronounced drop in the viscosity of the matrix, the material was observed to reach a limit of compaction.

Based on these considerations and in order to investigate the whole thermo-chemical behavior of the material, the standard manufacturing cure cycle (Fig. 3a) was modified. The adjusted one (see Fig. 5) consists in heating the prepreg sample at a constant rate of $2^{\circ} \mathrm{C}$ then applying an isothermal first dwell at $70^{\circ} \mathrm{C}$ during $50 \mathrm{~min}$. According to the tested cycles, we assume that this duration is sufficient to ensure a compaction limit that does not affect the thermal expansion of the material without inducing a chemical shrinkage of the matrix. Samples are then heated at a constant rate of $4^{\circ} \mathrm{C} / \mathrm{min}$ up to $160^{\circ} \mathrm{C}$ in order for the chemical reaction to start in the isothermal part of the second dwell. The material is cured at this temperature for $210 \mathrm{~min}$ then cooled to the ambient temperature with a ramp of $2^{\circ} \mathrm{C} / \mathrm{min}$.

\subsection{Thermo-chemical strains evolutions during curing}

Three laminate samples of the M21/IMA prepreg were cured according to adjusted manufacturing cure cycle. Only unidirectional configurations were tested in this study, the material was initially supposed to be transversely isotropic. Displacements raw data were firstly measured on two specimens simultaneously along both transverse directions of 
the unidirectional material: through the thickness and in plane directions, whereas the third laminate sample was tested through its thickness and along the axial direction of fibers. The estimated deformations of the three samples along the three directions are presented in Fig. 5 together with the simulated degree of cure and the imposed thermal cure cycle. Four phases can now be distinguished to characterize the thermo-chemical behavior of the material.

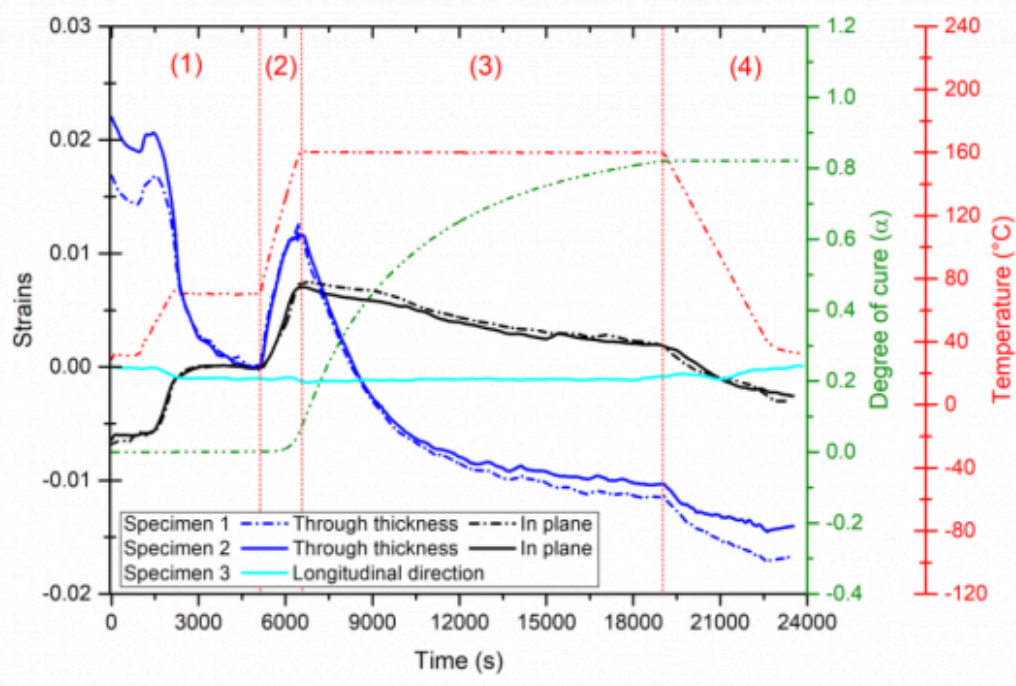

Fig. 5. Comparison between the deformations along three directions together with the estimated degree of cure and the thermal cure cycle

During phase 1 the material is still uncured. The first isothermal step is maintained at $70^{\circ} \mathrm{C}$ for 50 min. The compaction step of the material prior to curing occurs separately from the thermal expansion phenomenon. The two first samples undergo a maximal average compaction of $1.85 \pm 0.1 \%$. The comparison between the developments of the estimated strains along the three directions reveal an anisotropic behavior. Both samples exhibit bigger thickness changes during the compaction step compared to the in plane direction where the compaction effect is likely to be negligible. Along the longitudinal direction, the material is contracted during the totality of the cure cycle due to the negative coefficient of thermal expansion of carbon fibers and no compaction effect is observed. All the estimated strains were zeroed at the end of the compaction stage to compare the thermo-chemical behavior of the material during the curing. During phase 2 strains are estimated along both directions while the material stills at the liquid state. The expansion through its thickness is much higher comparing to the in plane direction. During phase 3 almost the whole crosslinking reaction of the matrix occurs during the isothermal step. Strains are directly linked to the cure shrinkage of the material. A large drop is visible in the through thickness direction while it is less important in the in-plane direction. Through the longitudinal direction, the deformation is rather unaffected and it remains constant during the isothermal dwell. During phase 4 strains decrease due to the thermal contraction of the material.

In order to estimate the CTE along both transverse directions and in both uncured and cured state of the material, the total induced strains were plotted versus the temperature. Such strains are directly linked to the temperature increment (see (Eq. (3)). In Fig. 6a the evolution of the through thickness deformation is given as an example. During the heating ramp, the slope of the linear zone represents the CTE of the material at its liquid state. The slope of the curve during cooling gives the CTE in the cured state. The estimated CTE are recapitalized in Table 2.

Table 2. Estimated values of CTE for the M21/IMA 
A Three-Dimensional Thermo-Chemical Characterization During the Whole Curing Cycle of a...

\begin{tabular}{lcc}
\hline $\mathbf{1 0 ^ { - 6 } \mathbf { K } ^ { - 1 }}$ & CTE through thickness & CTE in plane \\
\hline Uncured state & $182 \pm 3$ & $105 \pm 5$ \\
\hline Cured state & $55 \pm 4$ & $39 \pm 4$ \\
& Dilatometer $: 52 \pm 2$ & Dilatometer : $35 \pm 1$ \\
\hline
\end{tabular}

The estimated average values of the CTE through the thickness are proved to be higher compared to the in plane direction while the material is still at the liquid state but also when it is fully cured. The CTEs of the cured material were also measured using a linear dilatometer Linseis L 75 HXLT. Both transverse directions were investigated using specimens that were cut from the laminate samples after curing. The estimated values show a good agreement with the CTE obtained by the PvT HADDOC. The M21/IMA unidirectional laminate investigated in this research is thus fully orthotropic and does not have transversely isotropic properties. Such behavior is presumed to be related to the presence of interleaf layers of resin $[11,12]$.

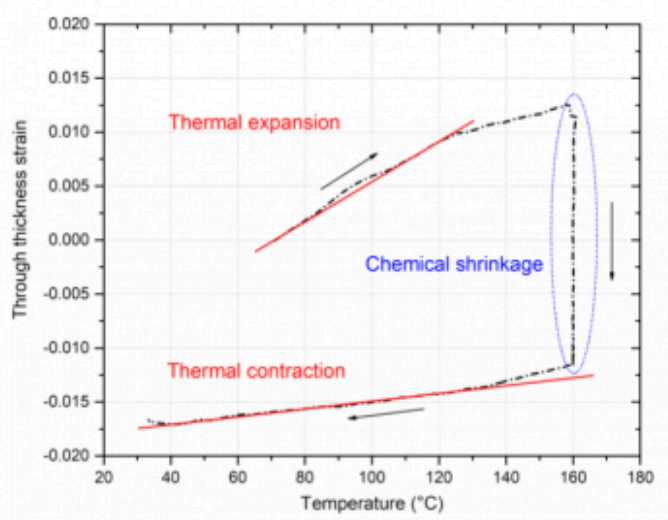

(a)

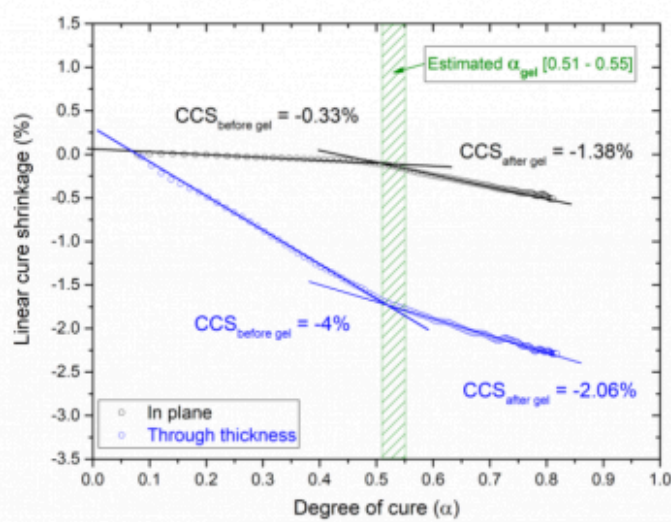

(b)

Fig. 6 (a) Through- thickness strain as a function of the temperature (b) Measured chemical shrinkage of specimen 1

Chemical strains, on the other hand, are directly linked to the cure shrinkage of the resin that occurs during crosslinking. After the determination of the linear CTE, the variation of the cure shrinkage $\left(\varepsilon^{\text {chem }}\right)$ along both directions is deduced by subtracting the thermal part $\left(\varepsilon^{\text {therm }}\right)$ from the measured total strains $\left(\varepsilon^{\text {tot }}\right)$ (Eq. (2)) to eliminate the thermal effect during the isothermal step. The CTE dependence is assumed to be linear with the degree of cure following a mixture rule between the uncured and the fully cured values of CTE (Eq. (4)). In order to estimate the CCS of the M21/IMA material, the variation of the chemical strains is plotted versus the degree of cure incorporating the cure kinetics model. Fig. 6b illustrates the dependence of the chemical shrinkage (of the tested specimen 1 as an example) on the degree of cure and the different slopes before and after gelation. The slope changes greatly around the gel point of the matrix that is estimated for the M21 system between 0.51 and 0.55 [4]. The average values of the estimated CCS in both directions for the tested samples are presented in Table 3. It is clearly shown that the material behavior is anisotropic. The total shrinkage through the thickness direction reaches $-2.29 \%$ whereas it is only $-0.5 \%$ in the plane direction. 


$$
\begin{gathered}
\varepsilon^{\text {chem }}=\varepsilon^{\text {tot }}-\varepsilon^{\text {therm }}=\int_{0}^{t} \operatorname{CCS} \frac{\partial \alpha}{\partial t} d t \\
\varepsilon^{\text {therm }}(t)=\int_{0}^{t} \operatorname{CTE}(t) \frac{\partial T}{\partial t} d t \\
\operatorname{CTE}(t)=\operatorname{CTE}(\alpha(t))=\operatorname{CTE}_{\text {uncured }}(1-\alpha(t))+\operatorname{CTE}_{\text {cured }} \alpha(t)
\end{gathered}
$$

Table 3. Average values of CCS for $160^{\circ} \mathrm{C}$ isothermal cure for the M21/IMA

\begin{tabular}{ccc}
\hline$\%$ & CCS through thickness & CCS in plane \\
\hline Before gel & $-3.83 \pm 0.3$ & $-0.27 \pm 0.04$ \\
\hline After gel & $-2.07 \pm 0.1$ & $-1.4 \pm 0.09$ \\
\hline
\end{tabular}

\section{Conclusions}

In this study, the PvT Haddoc device was used to investigate the HEXCEL's M21/IMA prepreg behavior during curing. The manufacturer's recommended cure cycle for this type of material was adjusted in order to separate the coupled phenomena taking place during the early stage of the curing process, i.e., thermal expansion, compaction and chemical shrinkage. Thanks to this experimental set up, it was possible to follow the compaction mechanism prior to cure. The material showed an anisotropic compaction behavior at the uncured state that occurred only through its thickness compared to the in-plane transverse direction. The exact thermal expansion and chemical contributions were calculated along both transverse directions of the unidirectional laminate. The CTE of the M21/IMA were estimated not only at the cured state of the material but also when it stills uncured. Such information is quite important to prevent to erroneous shape predictions and inaccurate tool compensation, as CTE data for this material was not available, especially when measured on thick laminates and not simply on single plies. Finally, the CCS of the material were estimated before and after gelation of the matrix. The large amount of the through thickness cure shrinkage took place before gelation with a measured CCS of about $-3.83 \%$. In the in plane direction, the measured chemical shrinkage was lesser and varied inversely compared to the through thickness direction. Based on these considerations, the M21/IMA material was shown to be fully orthotropic.

\section{Acknowledgements}

The authors would like to thank Nicolas Lefevre for the help on the designing and machining of setup.

The authors would like to acknowledge Hexcel Industries for supplying the material.

\section{Bibliography}

[1] Tanimoto T. Improving the fatigue resistance of carbon/epoxy laminates with dispersed-particle interlayers. Acta. Mater. 1998; 46(7):2455-2460. Doi: 10.1016/S1359-6454(98)80028-1

[2] Yasaee M, Bond IP, Trask RS, Greenhalgh ES. Mode I interfacial toughening through discontinuous interleaves 
A Three-Dimensional Thermo-Chemical Characterization During the Whole Curing Cycle of a...

for damage suppression and control. Compos. Part A, Appl Sci Manuf. 2012; 43(1):198-207. doi:10.1016/ j.compositesa.2011.10.009

[3] M. Péron, R. Cardinaud, N. Lefèvre, et al. "PvT-HADDOC: A multi-axial strain analyzer and cure monitoring device for thermoset composites characterization during manufacturing”. Compos Part A, Appl Sci Manuf. Vol. 101, pp 129-142, 2017.

[4] Abou Msallem, Y., Jacquemin, F., Boyard, N., Poitou, A., Delaunay, D., \& Chatel, S. (2010). Material characterization and residual stresses simulation during the manufacturing process of epoxy matrix composites. Composites Part A: Applied Science and Manufacturing, 41(1), 108-115. https://doi.org/10.1016/j.compositesa.2009.09.025

[5] J Bailleul, J., Guyonvarch, G., Garnier, B., Jarny, Y., \& Delaunay, D. (1996). Identification des propriétés thermiques de composites fibres de verre/résines thermodurcissables Application à l'optimisation des procédés de moulage. Revue Générale de Thermique, 35(409), 65-76. https://doi.org/10.1016/S0035-3159(96)80047-X 1996

[6] Nawab, Y., Tardif, X., Boyard, N., Sobotka, V., Casari, P., \& Jacquemin, F. (2012). Determination and modelling of the cure shrinkage of epoxy vinylester resin and associated composites by considering thermal gradients. Composites Science and Technology, 73(1), 81-87. https://doi.org/10.1016/j.compscitech.2012.09.018

[7] Nawab, Y., Boyard, N., Sobotka, V., Casari, P., \& Jacquemin, F. (2011). A device to measure the shrinkage and heat transfers during the curing cycle of thermoset composites. Advanced Materials Research, 326, 19-28. https://doi.org/ 10.4028/www.scientific.net/AMR.326.19

[8] Belnoue JPH, Nixon-Pearson OJ, Ivanov D, Hallett SR. A novel hyper-viscoelastic model for consolidation of toughened prepregs under processing conditions. Mech Mater. 2016; 97:118-134. doi:10.1016/j.mechmat.2016.02.019

[9] Ledru Y, Bernhart G, Piquet R, Schmidt F, Michel L. Coupled visco-mechanical and diffusion void growth modelling during composite curing. Compos Sci Technol. 2010; 70(15):2139-2145. doi:10.1016/j.compscitech.2010.08.013

[10] Nixon-Pearson O, Belnoue J-H, Ivanov D, Potter K, Hallett S. An experimental investigation of the consolidation behavior of uncured prepregs under processing conditions. J Compos Mater. 2017; 51(13):1911-1924. Doi: 10.1177/ 0021998316665681

[11] Kappel E, Prussak R. On abnormal thermal-expansion properties of more orthotropic M21E/IMA carbon-fiberepoxy laminates. Compos Commun. 2020; 17(October 2019):129-133. doi: 10.1016/j.coco.2019.11.014

[12] Frerich, T., Brauner, C., Jendrny, J., \& Hermann, A. S. (2019). Modeling the influence of interleaf layers in composite materials on elastic properties, thermal expansion, and chemical shrinkage. Journal of Composite Materials, 53(17), 2415-2428. https://doi.org/10.1177/0021998319830165

PDF automatically generated on 2021-05-24 21:18:08

Article url: https://popups.uliege.be/esaform21/index.php?id=2067

published by ULiège Library in Open Access under the terms and conditions of the CC-BY License (https://creativecommons.org/licenses/by/4.0) 